\title{
Memorias feministas en disputa y puentes rotos entre los años setenta y los años ochenta*.
}

* Fecha de recepción: 27 de octubre de 2015. Fecha de aceptación: abril de 2016.

\section{( Catalina Trebisacce ${ }^{* * *}$}

** IIEGE / UBA.

Palabras clave:

Argentina, feminismo, memoria, desacuerdos.

Key words:

Argentina, feminism, memory, desagreements.

\begin{abstract}
embellishing or forgetting different pages from the history(ies) of feminism(s). The present paper seeks to analyze the different memories that have been constructed, either by the successor feminism or by academic productions, over argentinien feminism during the decade of the 70. We shall argue that the memories produced by both of them (academics and activists) carry the marcs, on the one hand, of political desagreements that translate in silences, and on the other hand, of the anxieties and misunderstandings at the time of interpreting and situating the feminist experience of the seventy.

Abstract Feminist Memories, as every other political memory, have been a matter of inter-
est, passion and dispute. Different genealogies have been made by remembering,
\end{abstract} of

\section{Resumen}

Las memorias del feminismo, como cualquier otra memoria política, han sido materecordando, ensalzando y olvidando distintas páginas de la(s) historia(s) del(os) el feminismo argentino de la década del setenta por parte del feminismo sucesor, por un lado, y de las producciones académicas, por otro. Se sostendrá que las memorias acuerdos políticos que se tradujeron en silencios y, por otra parte, de ansiedades y de equívocos a la hora de interpretar y situar la experiencia feminista de los años setenta. 
1. Pedro afirma que hacia comienzo de la década del setenta existieron pequeños grupos de mujeres de clases medias y altas que se volcaron al feminismo. Mujeres que, algunas de ellas, tenían contactos con las cúpulas militares que sometían al país. Por su parte, Chaperon sostiene que en los inicios de la década del sesenta, ministas pero que estuvieron ligadas al proceso de modernización de la sociedad, y no a su politización (en el sentido restringido del término).
Las memorias del feminismo, como cualquier otra memoria política, han sido materia de interés, de pasiones y de disputas, tanto en el interior del propio feminismo como también en el campo de los estudios académicos interesados en narrar estas historias. Se han elaborado diferentes genealogías que han sabido recordar, ensalzar y olvidar distintas páginas de la(s) historia(s) del(os) feminismo(s). Sylvie Chaperon (1995) analizó algunos de los silencios producidos por el feminismo francés iniciado en la década de los setenta respecto de su predecesor. Según la autora, el Movimiento de Liberación de las Mujeres (Mouvement de libération desfemmes, MLF) declaró el año de su propio nacimiento como l'année zero del feminismo. Declaración que habría tomado, sin someter a serio escrutinio, buena parte de la bibliografía académica orientada al estudio de la historia del feminismo francés. Según Chaperon, en la década del setenta se produce un proceso de radicalización del feminismo a partir, por un lado, de los acontecimientos desatados pos Mayo Francés y, por otro, como consecuencia de la llegada de mujeres militantes de izquierda que, desencantadas de sus partidos, se iniciaron en el feminismo. Para este nuevo feminismo radicalizado, las expresiones de la década anterior se volvieron deseables de olvido.

Joana Maria Pedro (2006), estudiando la historia del feminismo en Brasil en la década del setenta, encontró síntomas similares a los que señalados por Chaperon. Pedro afirma que tanto en los relatos militantes como en la historiografía brasileña se instituyó como fecha de inicio del feminismo vernáculo de la segunda ola el año 1975. En ese año, Brasil aún se encontraba bajo una dictadura militar, pero la declaración de las Naciones Unidas del Año Internacional de la Mujer abrió la posibilidad y la excusa para la reorganización de las mujeres, provenientes en su mayoría de las izquierdas revolucionarias. La autora sostiene que, sin embargo, esta periodización silencia la experiencia de un feminismo anterior desarrollado a comienzos de la década de los setenta, encabezado por mujeres de clase pudientes y de contactos políticos reprobables para la izquierda. ${ }^{1}$ Pedro afirma que este relato de origen fue resultado de "disputas de poder entre diversos grupos feministas, y entre estos y los diversos personajes envueltos en la lucha contra la dictadura militar [...] El feminismo en el Brasil de la década de 1970 tiene historias entrecruzadas y conflictivas" (2006: 250).

Las memorias del feminismo argentino, más específicamente porteño, de los años setenta son aún fragmentadas y escasas pero contienen ya las marcas de sutiles disputas más o menos evidentes, más o menos conscientes, entre distintos actores (antiguas feministas, feministas posteriores y contemporáneos, académicas feministas, etc.). Sobre estas disputas versará el presente artículo que iniciaré con algunas notas de campo y entrevistas que tempranamente me advirtieron de la existencia de estas contiendas. Las advertencias recabadas orientaron mi atención hacia las militantes feministas de la década siguiente (tiempo de cruciales transformaciones para el feminismo) y hacia las académicas que en los últimos años se ocuparon de la historia del movimiento local. De modo que, siguiendo los indicios de mi trabajo de campo, el artículo centrará su análisis en dos instancias de producción de memorias del feminismo de los setenta. Por un lado, en las memorias elaboradas por la agrupación feminista más destacada de los años ochenta, la Agrupación de Trabajo y Estudio sobre la Mujer, más conocida por su sigla, ATEM, a través de su publicación anual, la revista Brujas. Y, por otro lado, en las narrativas que se produjeron en ocasión de un homenaje a las feministas de los años setenta organizado por académicas y feministas en el Museo Roca en el año 2002. Dicho evento fue de suma influencia para las producciones académicas, eminentemente historiográficas, que se produjeron en los años subsiguientes. A partir de estos análisis, se sostendrá que los relatos producidos a raíz de estas dos instancias llevan las marcas, en un caso, de desacuerdos políticos que se tradujeron en silencios y, en otro, de ansiedades y de equívocos a la hora de interpretar y situar la experiencia feminista de los años setenta. 
Antes de abocarme a este análisis, expongo a continuación una breve caracterización de los feminismos porteños a los que haré referencia a lo largo del trabajo.

\section{Retratos de las dos generaciones de feministas porteñas}

En la primera mitad de la década del setenta, la ciudad de Buenos Aires, histórico escenario de diversas vanguardias artísticas, políticas y culturales, acogió el nacimiento de algunos grupos de militancia feminista que se autoinscribían en el llamado 'feminismo de la segunda ola'. Estos grupos fueron cartografiados tempranamente por Inés Cano (1982), quien además señaló las numerosas reagrupaciones que entre ellos se produjeron, dejando entrever la intensidad de actividades y encuentros que existieron por entonces. Ahora bien, toda esta proliferación de grupos y actividades estuvo concentrada en torno a dos agrupaciones específicas, la Unión Feminista Argentina (UFA) y el Movimiento de Liberación Feminista (MLF). Estas fueron luego interpretadas como los antecedentes del feminismo contemporáneo. De modo que las memorias que se tratarán aquí se circunscriben casi exclusivamente a las de estas dos agrupaciones autónomas. ${ }^{2}$

La Unión Feminista Argentina se constituyó a partir de la repercusión de declaraciones hechas por María Luisa Bemberg en ciertos medios gráficos al momento del estreno del film Crónica de una señora, compuesto con un guion de su autoría. En aquella ocasión, Bemberg se declaró feminista y pronto recibió correos de mujeres interesadas en saber de qué se trataba eso. María Luisa ya había entrado en contacto con Gabriela Christeller, una mujer italiana con título nobiliario que también estaba interesada en estos asuntos. Juntas impulsaron, primero, grupos de lectura en el Café Tortoni, tradicional bar de Buenos Aires, y, luego, junto a otras le dieron forma a la UFA y le destinaron un lugar (al menos en los primeros años) en un local del barrio de Chacarita, propiedad de la familia Christeller. A pesar de la trascendencia de estas figuras, la agrupación sostenía la importancia de desarrollar una militancia horizontal, procurando desandar las jerarquías que pudieran constituirse de facto. Se abocaron especialmente a realizar trabajos de concientización (concienciación) de las mujeres y a denunciar los patrones culturales opresivos para estas. Asimismo, declaraban de importancia para el desarrollo de la militancia feminista que las diferencias políticas que pudieran existir entre ellas no se expresaran en el interior del grupo (Trebisacce, 2014).

Por su parte, el Movimiento de Liberación Feminista se desarrolló compartiendo buena parte de los intereses y actividades de la UFA. También se constituyó a partir de las repercusiones mediáticas de su fundadora, María Elena Oddone, quien intervino en un diario de tirada masiva declarándose feminista. Luego de esta instancia, ella también recibió llamadas y cartas de mujeres interesadas (Oddone, 2001). Al igual que la UFA, el MLF se abocó a trabajos de concientización y de crítica a los patrones culturales establecidos. Y también rechazó la identificación de la militancia feminista con algún tipo de otra militancia política. La diferencia que suele declararse entre una y otra agrupación feminista autónoma estriba en el hecho de que el MLF aceptaba las jerarquías organizativas y la dirección de María Elena Oddone. Sin embargo, cabría señalar que existe otra diferencia explicitada a medias, y tan solo por algunas de las militantes de la UFA, que habla de una sospecha sobre la posible adscripción de Oddone a ideología política de derecha. Dicha adscripción fue varias veces negada por la directora del MLF, aunque sus intervenciones, especialmente en la década siguiente, habrían también proporcionado algunas razones para sostenerla. Tanto la UFA como el MLF, que se constituyeron en los primeros años de la década del setenta, se disolvieron hacia 1976 con el golpe militar y el avance del clima opresivo que se instaló en la sociedad toda, y no solo entre los militantes políticos.
2. Por 'autónoma' entiendo a aquella militancia que se constituyó de modo independiente de agrupaciones partidarias. Y aunque en este período existieron dos secciones de mujeres de partidos que entablaron algún vínculo con la UFA o con el MLF. Me refiero a la sección de mujeres Muchacha del Partido Socialista de los Trabajadores (PST) y al Movimiento Feminista Popular (MOFEP) del Frente de Izquierda Popular (FIP). Ellas no han sido consideradas en el análisis porque fueron experiencias aún pequeñas y porque las memorias de la militancia feminista no les otorga un lugar central como sí lo hacen con las agrupaciones autónomas. Para un estudio sobre las otras experiencias de feminismo de secciones partidarias, consultar Trebisacce, 2013a y 2013b. 
3. Quisiera advertir que el presente artículo no tiene por objetivo central desplegar las diferencias y las disputas entre los grupos feministas arriba expuestos. Ellas aparecerán en el marco del análisis de los procesos de construcción del pasado procurando dar cuenta de las razones de las narrativas generadas. 4. En la mayoría de los casos, conservo los nombres reales porque muchas militantes me expresaron, una y otra vez, su malestar con el "ocultamiento" de sus nombres. Solo en algunas ocasiones, en las que evalué que la exposición era desmedida y la argumentación no se entorpecía, decidí ficcionalizarlos.

5. Tiempo en el que trabajé en su archivo personal (2009/2010/2011). El archivo, o parte de él, fue recientemente donado al Centro de Documentación e Investigaciones de las Culturas de Izquierda en la Argentina.

6. Las jornadas fueron realizadas en el año 2004 por investigadoras jóvenes de la Universidad de Buenos Aires que pugnaban por el conseguir recomidad para estos estudios en su campo disciplinar.

7. Entrevista realizada por la autora en julio de 2008. Sobre esta posible censura a Femimundo volvió en la entrevista siguiente en noviembre de 2008 , repitiendo la misma información y los mismos silencios.
El feminismo que se inicia en la década del ochenta lleva otras marcas. Sus filas se vieron ampliadas especialmente por la participación de mujeres que en la década anterior se encontraban asociadas a agrupaciones de izquierda. Aparece como un ejemplo de este nuevo feminismo la "Asociación de Trabajo y Estudio de la Mujer" (ATEM) que pronto se consolida como la agrupación más destacada, consiguiendo el consenso necesario para marcar la dirección de la agenda de militancia feminista del período. Militancia que ahora sí se declaraba anticapitalista y expresaba compromisos con la lucha de los movimientos por los derechos humanos que por entonces iban ganando las calles.

Desde sus inicios, ATEM tuvo como uno de sus objetivos medulares impulsar el movimiento local propiciando la difusión de las distintas corrientes del feminismo internacional y generando debates en el interior del feminismo local a partir de jornadas y encuentros sistemáticos. Los debates dentro del feminismo local se dieron en los primeros años y estuvieron especialmente dirigidos a dar disputas y establecer acuerdos con las viejas militantes feministas de los setenta que en estos años se encontraban nucleadas o en la Organización Feminista Argentina (OFA) con María Elena Oddone, o en "Lugar de Mujer". En el marco de esta tarea, ATEM necesitó (re) componer una historia del feminismo en la Argentina y volvió los ojos hacia el pasado buscando reconocer (o no) antecedentes, compañeras de ruta y/o adversarias. De aquí que sea de especial importancia el análisis de las memorias feministas producidas por esta agrupación. Por otra parte, también resultan fundamentales estas memorias porque buena parte de las académicas que ingresan en los institutos de investigación universitarios hacia mediados los noventa mantuvieron contacto con esta agrupación militante cuando no fueron directamente militantes (Besse y Trebisacce, 2013).

Realizada esta breve caracterización de las agrupaciones feministas de los años setenta y ochenta, despliego a continuación el análisis de las disputas, los olvidos y las ansiedades que tuvieron lugar en la producción de memorias (militantes y académicas) sobre el feminismo de los setenta. Lo haré a partir de un trabajo analítico sobre los indicios aparecidos en el contexto de mi trabajo de campo, las entrevistas con militantes de los años setenta y la exploración documental de publicaciones producidas a partir de las décadas siguientes. ${ }^{3}$

\section{Comenzando por los síntomas: malestares y denuncias}

Sara Torres (militante de la UFA) 4 fue mi primer contacto y mi informante clave por el tiempo de tres años. ${ }^{5}$ También lo fue de muchas otras investigadoras. Sara no solo conserva uno de los archivos más importantes de aquella época, sino que se encuentra a disposición de quien solicite su testimonio de aquellos años.

En la primera entrevista que mantuve con Sara, ella encontró ocasión para comentarme de un malestar que sintió en el marco de unas jornadas académicas de historia que habrían procurado dar tratamiento al feminismo argentino de la década del setenta. ${ }^{6}$ El comentario de Sara se produjo mientras hablábamos del cortometraje Femimundo, de María Luisa Bemberg (militante de la UFA). "Se presentó ahí [el corto] y ya se presentó cortado. [...] Yo estaba furiosa. Le sacaron esa parte. Debe ser porque era la única parte actuada y aparece la hija de María Luisa y el marido, y yo les daba el volante y ella lo miraba y lo tiraba. Y como estaba la imagen de ella, le deben haber pegado una tijereteada al original". ${ }^{7}$ Me quedé dudando si ella atribuía un ánimo de censura a las organizadoras del evento, que habrían deseado ocultar los vínculos de la feminista con figuras destacables de la oligarquía porteña, o si desconfiaba de 
círculo familiar de María Luisa Bemberg, quienes quizás habrían deseado quitar esas imágenes para desvincular a los familiares de la obra de la cineasta.

En ocasión de otra visita que realicé a su casa, Sara me propuso discutir un texto de mi autoría sobre la UFA. El texto era un trabajo exploratorio, las primeras líneas de mi proyecto de doctorado en las que recuperaba los pocos pero valiosos trabajos existentes hasta el momento. Sara me señaló que encontraba cosas con las que desacordaba, en mi texto y en mi bibliografía. Cuando le pedí especificaciones sólo dijo "con el enfoque". ${ }^{8}$ En una y otra ocasión no conseguí mayores precisiones pero, en cualquier caso, ambos episodios quedaron marcados como ocasiones para la expresión de una denuncia formulada a medio camino que me puso en alerta.

Por otra parte, a lo largo de 2008 y 2009 sostuve una serie de conversaciones telefónicas con Leonor Calvera (militante de la UFA entre 1970 y 1973) con el objetivo de concertar una cita que no se produjo sino hasta diciembre de $2012 .{ }^{9}$ Mientras el encuentro se hizo esperar, mis primeros registros de campo en torno a Leonor los produje a partir de dichas comunicaciones telefónicas. En una de las primeras conversaciones, cuando me presenté y expliqué la razón de mi llamado, Leonor expresó sorpresa e ironía (y lo hizo insistentemente en varias ocasiones luego) ante el hecho de que el CONICET y la Facultad de Filosofía y Letras estuvieran interesados en financiar y permitir la investigación sobre la experiencia del feminismo de los setenta. En la entrevista que finalmente compartimos, Leonor se despachó con críticas a la academia y deslizó suspicacias sobre el feminismo posterior. También se refirió al homenaje realizado en el Museo Roca en 2002 por académicas y feministas. A su propósito, dijo:

L. C.: Las académicas en estudios de género buscaron de todas maneras aplastar lo que habíamos hecho en la UFA [...] Teóricamente era un homenaje que querían hacer [...] Dijeron que era un homenaje, y fue una cosa de terror [...] todo estaba mal, todo era manejado por la tal Rossi [académica y militante feminista desde los ochenta], todo estaba mal, todo era otra cosa, todo no era, todo no habíamos hecho esto, lo habíamos hecho lo otro, habíamos estado... Llegó un momento “¿qué estoy haciendo acá?, soy masoquista”, y dije "me voy”, hice así y me fui. Nadie me frenó, eh. [...]

C. T.: Pero ¿cuáles eran las carencias de las que las acusaban?

L. C.: Nada, no sé. Todavía no sé de qué nos acusaban.

C. T.: ¿En qué punto...? Ah, no saben.

L. C.: No. Era, era todo mal. Todo estaba mal. Todo lo que habíamos hecho, lo que no habíamos hecho.

\section{C.T. : ¿Al criterio de quién?}

L. C.: Al criterio de la tal Rossi, por ejemplo, la Gallo [académica y feminista], que Ilevaba la voz cantante. "Porque el ochenta, porque el ochenta" ¿El ochenta?. ${ }^{10}$

En la misma jornada de homenaje en el Roca, tuvo lugar otra denuncia que quedó registrada en las grabaciones del evento. Marta Miguelez (militante de la UFA) criticó una reconstrucción de la historia del feminismo realizada por una investigadora y militante feminista de los años ochenta:

Lo que a mí me sorprende es que de pronto hay lo que dice Leonor ahora, hay como una negación que se hace desde hoy mismo del feminismo de los setenta
8. Notas de campo, apuntadas luego de la visita a la casa de Sara Torres el 25 de mayo de 2009.

9. Notas de campo después de una charla telefónica en mayo de 2009. Durante 2008 y 2009 hablé por teléfono y concreté numerosas citas con Leonor que ella canceló sistemáticamente unas horas antes de producirse. Hacia mediados de 2012, Leonor se comunicó conmigo para preguntarme por mi trabajo. Desde entonces estuvimos intentado nuevamente reunirnos, ella volvió a cancelar en varias ocasiones pero, finalmente, lo conseguimos en los últimos días de diciembre del 2012. Además de los problemas personales que por estos años atravesó Leonor. estimo que las dificultades extraordinarias que me significó la adquisición de este testimonio encuentran sus razones en la conflictiva relación que ella entabló con las académicas.

10. Entrevista realizada por la autora en diciembre de 2012. Los nombres verdaderos de las académicas los he reemplazados por otros. 
11. Testimonio de Marta Miguelez. Desgrabación del Homenaje a Feministas de los setenta, organizado por el Encuentro Feminista, 9 de octubre de 2002 en el Museo Roca. Material cedido por la Dra. Mónica Tarducci. que es algo que yo dije al principio, yo he descubierto leyendo un texto, digo, Mariana Mezquita justo está acá, que es una de las autoras, donde dice que el feminismo empieza en Buenos Aires en Argentina en la segunda mitad del ochenta, o sea aproximadamente en el ochenta y cinco, y yo creo que esto es una distorsión... ${ }^{11}$

De modo que aquel evento celebratorio se convirtió en causa de denuncias tanto para Leonor como para Marta, y sus relatos, en advertencias para mi investigación. La primera sugería que la experiencia del feminismo de los setenta había sido contemplada con una vara equívoca desde la academia, que le correspondía en todo caso al feminismo posterior. Mientras que la segunda señalaba, directamente, una paradójica invisibilización del feminismo de los setenta.

\section{El nuevo feminismo con el signo de los ochenta}

Los años ochenta representaron una transformación radical en la militancia feminista local, pues sus filas se ampliaron y complejizaron a partir de la incorporación de militantes nuevas con diferentes trayectorias y consideraciones respecto de los objetivos de la lucha. En esta década confluyeron algunas reediciones de los grupos militantes de los setenta, como la Organización Feminista Argentina (OFA), con algunas nuevas organizaciones, como ATEM (Chejter, 1996). Paralelamente, algunas antiguas militantes de la UFA fundaron una casa cultural que les dio cobijo no solo a antiguas militantes sino también a nuevas mujeres provenientes, en su mayoría, de la agrupaciones izquierda que retornaban de sus exilios buscando espacios de participación feminista. ${ }^{12}$ En "Lugar de Mujer", como se llamó a la casa, se desarrollaron actividades culturales y se diseñaron las campañas centrales de aquellos años (Patria Potestad Indistinta y Ley de Divorcio Vincular). Allí tuvieron sus reuniones los nuevos frentes feministas, como "Movimiento Feminista" o luego la "Multisectorial de la mujer". En este período de apertura democrática, las feministas también parecían florecer por todas partes, encontrarse y mezclarse un poco.

Con el paso de la década, la efervescencia fue cediendo y se produjo una reconfiguración en el escenario feminista porteño, que poco a poco fue desplazando las expresiones del viejo feminismo y consagrando a ATEM como la agrupación más importante. ATEM fue la única agrupación feminista que consiguió, y consigue, conservarse en el tiempo. En 2012, celebró sus treinta años de militancia, lo que hace de este caso uno más bien anómalo para el contexto local. Sus militantes (en adelante, 'atemas') se ocuparon de la tarea de llevar adelante la difusión del feminismo en la Argentina, a través de la realización de las "Jornadas Feministas", y de la edición y divulgación de la revista Brujas, que llega ya casi al número 40. A fuerza de trabajo y tenacidad, ATEM logró durante años marcar la agenda de la militancia feminista local, a tal punto que aunque en la actualidad no sea esta la situación, sus posicionamientos ante temas controvertidos consiguen mantener una posición de hegemonía en el escenario local.

Por estos particulares motivos que hacen a la historia y a la actualidad de ATEM, y por efecto de algunas de mis notas de campo que señalaban suspicacias para con el feminismo de los ochenta, entendí necesario detenerme a rastrear cuáles eran las memorias (si es que existían) que las atemas habían construido sobre el feminismo inmediatamente anterior. Pues considero que ATEM, en el desarrollo de su militancia, necesitó (re)componer una historia del feminismo en la Argentina. Como cualquier movimiento social, debió volver los ojos al pasado buscando reconocer a sus antecesores/as en la lucha. 
Al analizar los casi cuarenta números de Brujas, pueden diferenciarse al menos tres momentos en la publicación, cada uno con características diferenciales, en lo que refiere al tratamiento que producen en las memorias de las feministas precedentes. El primer período abarca desde el primer número de Brujas hasta el séptimo, que se publican entre 1983 y 1984, coincidiendo con el momento de más efervescencia en la confluencia de las distintas feministas que más arriba mencionaba. En este período, Brujas hace referencias prácticamente soterradas a la militancia feminista de los setenta. Se producen menciones personales a algunas exmilitantes, por ejemplo, en ocasión de la celebración de la publicación de un libro de Leonor Calvera ${ }^{13}$ o de un saludo de despedida por el fallecimiento de Inés Cano, ${ }^{14}$ pero en ninguna circunstancia se producen referencias a las agrupaciones específicas de las que fueron parte. Silencios sobre el feminismo anterior que no pasaron desapercibidos. María Elena Oddone (presidenta del MLF) en su autobiografía denunció el borramiento de su persona, afirmando: "lo que no se nombra no existe" (2001: 201). Marta Miguelez, por su parte también, confesó que sentía que se producía una falta de menciones, de nombre propios (de agrupaciones y de personas), sobre las memorias feministas de los setenta.

Asimismo, los primeros números de Brujas supieron informar sobre las técnicas de concientización creadas por las feministas norteamericanas como la herramienta revolucionaria del feminismo de la segunda ola. Y aunque estas técnicas se habían constituido en el eje central de la militancia feminista porteña de los setenta, la publicación de las atemas también supo silenciar toda referencia a la experiencia local. ${ }^{15}$

En este período, y como complemento necesario de estas políticas de distanciamiento - traducidas en invisibilización - del feminismo local predecesor, las atemas se centraron en procurar producir una definición propia de 'feminismo'. Varios artículos firmados por sus fundadoras estuvieron abocados a ello, y deben leerse como una discusión solapada con el feminismo precedente. ${ }^{16}$

Para la UFA, el feminismo convocaba

a mujeres pobres, negras y blancas, a trabajadoras explotadas, a amas de casa aprisionadas entre las rejas de la casa soñada, a estudiantes que despiertan ante el hecho de que ser atractivas sexualmente no es un logro culminante, a militantes que descubren que en el seno de los movimientos de liberación no son libres. El feminismo es, sin duda, una revolución que abarca a la mitad de la humanidad, sin distinción de condiciones ni de razas (Barancchini, 1973: 49).

Esta celebración del encuentro en la heterogeneidad fue repetida por varias de mis entrevistadas, que señalaban: "nos juntábamos por lo que nos unía, no por lo que nos separaba". ${ }^{17}$ Polemizando con esta posición, las mujeres de ATEM consideraban que era necesario "contextualizar el movimiento feminista [pues ello] es una necesidad que marca su crecimiento. El feminismo debe contextuar sus objetivos y sus luchas en el lugar en que actúa. En la Argentina, el feminismo debe tomar posiciones antiimperialistas, a favor de los derechos humanos y de la lucha de clases" (p.7). ${ }^{18} \mathrm{Y}$ delineaban como uno de los objetivos del feminismo "construir una realidad sin relaciones jerárquicas. Para ello es necesario cuestionar la propiedad privada, las opresiones nacionales, de clase, de raza, de etnia" (p. 7). ${ }^{19}$

En el séptimo número de Brujas se publicó un artículo en el que puede leerse una apretada caracterización del feminismo de los setenta, que permite comprender las distancias que las militantes de ATEM planteaban respecto del feminismo anterior:
13. Koifman, N. (circa 1983). A propósito de la presentación del libro El género mujer. En Brujas, año 1 núm. 1, p. 4. En esta ocasión, Koifman critica la presentación que Bernardo Neustadt realizó del libro de Leonor. defendiéndola, pero omite las referencias que ligan a la autora del libro con el feminismo de los años setenta y la presenta como una intelectual.

14. En el séptimo número de Brujas publica una despedida a Inés Cano con las siguientes palabras: "conocon las siguientes palabras: "cono-
cíamos tu trayectoria feminista de los años 70 y tu función de periodista comprometida con los problemas de la mujer(p. 15) pero, sin embargo, no se producen menciones a los grupos en los que Inés participó, como por ejemplo ALMA.

15. Quien se acercaba a participar de la UFA recibía un folleto titulado ¿En qué consiste ser miembro de UFA (Unión Feminista Argentina)? En él se detallaban las actividades por desarrollar necesarias para participar de esta agrupación, numeradas de la siguiente manera: “1) integrar uno de los grupos de concientización; 2) asistir a las reuniones generales; 3 ) abonar una cuota mensual y 4) integrar un grupo de trabajo“ (documento interno de la UFA, archivo de Sara Torres). De estas cuatro condiciones, según varias de mis entrevistadas, solo la primera era fundamental para la permanencia en la UFA. También en el MLF, si bien la experiencia no fue tan importante, la concientización fue un tema de esta organización. De hecho, el MLF dedicó en, el primer número de su publicación, Persona, un extenso artículo a explicar la centralidad de esta práctica para el feminismo de la organización.

16. Aparecen los artículos tales como: "Apuntes para una definición del feminismo en Argentina” (año1, núm. 3, p. 5), “¿Qué es para mí el feminismo?" (año 2, núm. 4, p. 4) o "El feminismo como ideología y como práctica política" (año 2, núm. 6, p. 4) y "El feminismo como movimiento político" (año 3, núm. 7, p. 9).

17. Entrevista con Sara Torres, de noviembre de 2008 . También se expresó en este sentido Marta Miguelez (entrevista de julio de 2009) y Gabriela Christeller (entrevista de abril de 2010).

18. Apuntes para una definición del feminismo en Argentina. En Brujas, año 1, núm. 3

19. Apuntes para una definición del feminismo en Argentina. En Brujas, año 1, núm. 3 
20. Bellotti, M. El feminismo como movimiento político. En Brujas, año 2, núm. 7 .

21. Navarro, M. (1992). El feminismo y Evita. En Brujas, año 11, núm. 18 año, noviembre.
22. Véase Bellotti, M. (1986). Primer Encuentro Nacional de Mujeres. En Brujas, año 4, núm. 10, noviembre, p. 30; Bellotti, M. (1988). 1ํㅡㄹ Encuentro de Feministas Lesbianas de Latinoamérica y el Caribe. En Brujas, año 6, núm. 12, marzo, p. 26; Bellotti, M. (1988). ¿Hacia un movimiento autónomo de mujeres? Los encuentros nacionales". En Brujas, año 6, núm. M. (191), V ntenla, M. y Bellotti, Latinoamericano y del Caribe. En Brujas, año 10, núm. 17, noviembre.
Hasta ahora, las tareas emprendidas por el feminismo en la Argentina han tenido las limitaciones propias de la escasez numérica de las militantes, la ausencia casi total de debate sobre ideas y las políticas, el conocimiento parcial de la realidad de las mujeres, la composición fundamentalmente de clase media urbana y los limitados contactos con otros sectores de mujeres.[...] En segundo lugar, las políticas feministas han adolecido hasta ahora de cierto grado de improvisación y desinterés por analizar la situación concreta de las mujeres en nuestro país e indagar en las diferencias que determinan las distintas posiciones de clase, raza o formas de sexualidad, todo lo cual genera muchas veces propuestas abstractas e inadecuadas a la realidad en nuestra sociedad (pp. 11-12). ${ }^{20}$

Un segundo momento en la publicación, en lo que respecta a sus políticas de memorias denle relación con el feminismo antecesor, abarca los números 8 a 26, entre 1984 y 1999, cuando mermaba la efervescencia de la militancia feminista porteña. En este extenso período se produce la aparición de una sección dedicada a rescatar del olvido a las mujeres feministas de la historia o a mujeres que, aunque no se declararon feministas, habrían desafiado los mandatos de su época contribuyendo a la emancipación femenina. Marysa Navarro, historiadora feminista y contribuidora de la revista de ATEM, explicita y fundamenta - justamente, en un artículo de Brujas - esta manera de intervenir sobre el pasado.

En casi todos los países donde se han desarrollado movimientos feministas en estas últimas décadas, las feministas han vuelto la mirada hacia el pasado para buscar sus raíces, enriquecer y fortalecer su comprehensión del presente, establecer continuidades e inscribir este nuevo conocer en una historia que ignora a las mujeres y su memoria. En muchos casos, esta preocupación ha tenido también el propósito de redescubrir figuras femeninas y recuperarlas para el feminismo (p. 31). ${ }^{21}$

Así es que en dicha sección se recuperaron las biografías de diferentes mujeres, feministas y no feministas, locales y extrajeras, como Alicia Moreau, Alfonsina Storni, Juana Rouco Buela - junto a otras mujeres anarquistas-, María Rosa Oliver, Flora Tristán, Emma Goldman y Carla Lonzi. Este gesto generoso de considerar feministas a quienes no se han reconocido como tales, ampliando las filas del feminismo, contrasta con la ausencia absoluta de biografías, historias o referencias sobre las militantes feministas de los años setenta de la Argentina. En las páginas de Brujas se han evitado hasta las más mínimas referencias de aquel feminismo. No se trata de un silenciamiento o un olvido, sino de una forclusión, una represión que no deja huella, y que debe ser entendida como un gesto político, como la decisión de no dar testimonio de la existencia de aquel feminismo.

En este período, los artículos centrales de la revista abandonaron las discusiones e intentos de definición del feminismo, lo que es evidencia de que se dejaban atrás las disputas con los espectros de la experiencia de los setenta, y orientan sus energías a plantear discusiones en torno a la autonomía del movimiento, que era lo que se encontraba amenazado por una incipiente institucionalización de algunas feministas. $^{22}$

Sin embargo, sorprende un tercer momento en la publicación, que se inicia en con el número 27 junto a la desaparición de la sección "Mujeres feministas en la historia" y a la aparición, aunque con más irregularidad, de la sección "Historias del feminismo". De la mano de este rediseño de la publicación, irrumpe una novedad en cuanto al tratamiento abierto de las memorias del feminismo de los setenta. En el número 27 de Brujas, de octubre de 2000, aparecieron por primera vez - después de casi dos décadas - los nombres propios de las agrupaciones feministas de los años setenta: 
UFA es el primero y se inicia en 1970. Una actividad insoslayable de esta agrupación fue la formación de grupos de concientización o autoconciencia [...] Realizaron muchas otras actividades: debates, volanteadas, testimonios filmados, reportajes en medios de comunicación, etc. [...] En todos estos volantes, hablan a las mujeres, apelando a la experiencia y a la identificación, con expresiones como "hermana... no estás sola... tus problemas no son individuales..." [...] Se habla de "opresión", “esclavitud”, “hermandad”, “liberación”, “nueva mujer”, “conciencia nueva”. El MLF, por su parte, creado en 1972, usa un lenguaje feminista radical, más agitativo y con un fuerte tono de denuncia, aunque sin dejar de lado las cuestiones ideológicas y conceptuales. Habla de patriarcado, sistema de dominación, poder despótico de todos los varones sobre las mujeres, de violencia (pp. 84-85, los subrayados son del original).23

El artículo continúa con la mención de otros grupos más pequeños, como Nueva Mujer, Muchacha del Partido Socialista de los Trabajadores y MOFEP del Frente de Izquierda Popular. Es destacable la cantidad y calidad de información volcada después de muchos años de evasión a cualquier referencia directa.

Unos números después, en el 32, de octubre de 2006, el feminismo de los años setenta se transformó directamente en tema y motivo de tapa. Bajo el título Feminismo socialista en los '70, ATEM otorgó un tratamiento extendido a aquella experiencia. Fue publicado un artículo explicativo e introductorio a cargo de las editoras, que daba el marco a tres extensos testimonios que se publicaron a continuación, de distintas militantes feministas de aquellos años, Mirtha Henault (Nueva Mujer-UFA), Ladis Alanis (UFA) y Sara Torres (UFA). En dicho artículo introductorio se explicaba el surgimiento del feminismo de los años setenta enlazado con las grandes luchas obreras, estudiantiles y campesinas, revoluciones anticolonialistas y socialistas:

La Unión Feminista Argentina (UFA), que alojó tendencias diversas, nace en Buenos Aires en el mismo período en que la resistencia contra la dictadura de Onganía alumbra el Cordobazo, crece el sindicalismo antiburocrático y clasista, se extiende la rebelión estudiantil, se desarrollan los grupos armados y las organizaciones políticas de izquierda y peronistas (pp. 63-64).24

Esta inscripción del feminismo en el contexto de radicalización política se enfatizó aún más en páginas siguientes, al sostener que la creciente represión desatada por la Triple A también tuvo a las feministas como parte de sus objetivos. "A partir de 1974 se enrarece el clima político, con un aumento de la represión ya anunciado por la masacre de Ezeiza [...] las tres A [...] asesinan y amenazan militantes políticos, activistas sindicales, periodistas, artistas. Las feministas no estuvieron excluidas de esta situación (p. 69).25

A pesar de que la serie de artículos y entrevistas admiten la composición heterogénea del feminismo de entonces, en el que convivían mujeres independientes y mujeres militantes de partidos políticos, y a pesar, también, de que los escritos iluminan la tensión existente en el interior del feminismo como efecto de su heterogeneidad, el objetivo de esta serie de artículos-entrevistas fue enfatizar las relaciones del feminismo de los setenta con la militancia de izquierda y el contexto de radicalización política. Evidencia de ello la constituye el título del número (Feminismo socialista de los ‘70) y la ausencia absoluta de cualquier referencia al Movimiento de Liberación Feminista (MLF) dirigido por María Elena Oddone, de quien difícilmente podría decirse que tuviera simpatía con la militancia de izquierda. De esta manera, en este período las atemas parecen haber procurado recuperar los años setenta dejando caer en el olvido a las expresiones que podrían resultar confusas o problemáticas para ellas.
23. Bellotti, M. (2000). Políticas y lenguajes feministas. En Brujas, año 19 , núm.27, octubre.
24. ATEM (2006). Feminismo socialista en los setenta. En Brujas, año 25, núm. 32, octubre.
25. Es verídico que las organizaciones feministas sufrieron tristes contactos con la Triple A, pero es necesario afirmar que las amenazas estuvieron ligadas no a su involucramiento con el proceso de radicalización política, sino a cuestionamiento a os mandatos morales. Fue una perpos mandatos morales. Fue una persecución moráta más que política en términos clásicos. De hecho, las amenazas más serias las recibió María Elena Oddone, quien se preocupaba de mantener bien diferenciada la militancia feminista de la militancia política. Curiosamente, las atemas hablan de unas amenazas a "otras" feministas, y evitan mencionarla. 
26. Documento consultado del archivo personal de Sara Torres.

27. Entrevista realizada por la autora en septiembre de 2009

\section{Memorias, interlocuciones, identidades y desidentificaciones}

Joël Candau sostiene que "la memoria no es una facultad más o menos fiel repositora del pasado tal y como este sucedió, sino una actividad compleja que, según lo que esté en juego y los conflictos personales y sociales, conserva, transmite, olvida, abandona, expulsa, destruye, censura, embellece o sublima el pasado" (2002: 87). Es por ello que las memorias, más que un simple relato sobre el pasado, encarnan una apuesta y un deseo presente en proyección a un futuro, en el que se encuentran involucrados varios/as interlocutores/as. Los primeros años de ATEM, en los que Brujas expresa una preocupación por producir una definición por un feminismo que no pusiera en suspenso otros vectores de opresión (tales como político, étnicos o económicos), algunas antiguas feministas radicalizaron sus viejas posiciones, entre las que María Elena Oddone es la más desatacada en esta empresa.

Recordemos que en esta década ingresan al feminismo (o se ponen en contacto con él) mujeres que habían participado en los setenta en distintas organizaciones de izquierda. Mujeres estas que, junto a las atemas, impulsaron tareas de alianza y apoyo para con la lucha llevada adelante por las Madres de Plaza de Mayo. En este contexto, Oddone fue protagonista de intervenciones muy controvertidas a partir de las cuales ganó una importante cantidad de adversarias. La triste actuación que más se le recuerda estuvo asociada a una carta que escribió y repartió en el marco de una actividad por la Patria Potestad Indistinta, en septiembre de 1985, en la que se refirió a las Madres de Plaza de Mayo y a la relación que esta agrupación mantenía con los grupos feministas:

Las presiones que reciben algunas de las integrantes del M. F. (Movimiento Feminista) para que este grupo adhiera a las Madres públicamente y se tenga un contacto frecuente con esas señoras, es resistido por unas pocas feministas, entre las que me encuentro, porque no vemos entre ambos grupos otra coincidencia que no sea la de ser mujeres, punto en común que no es suficiente para desarrollar una línea ideológica que conduzca a otras coincidencias que no existen. La popularidad en el país y en el extranjero adquirida por las Madres de Plaza de Mayo, ha llevado a algunas feministas a rendirles una adhesión fanatizada que les hace desdibujar los objetivos del M. F. ${ }^{26}$

La carta continúa con una descripción al estilo de la conocida teoría de los dos demonios a partir de la cual las estrategias político-armadas de los militantes de izquierda son comparadas con las prácticas de las Fuerzas Armadas. Como es de esperarse, esta carta de 1985 provocó el repudio de muchas mujeres del Movimiento Feminista y, finalmente, la expulsión de María Elena. Sin embargo, el objetivo de María Elena había sido señalar lo que consideraba un error de las nuevas generaciones de feministas.

Yo no hablaba en contra [de Las Madres de Plaza de Mayo]. Yo en las reuniones de Lugar de Mujer decía: "ellas tienen su trabajo, me parece muy bien, me parece muy bien, las admiro porque salieron cuando todavía estaban los militares y todo pero no tiene nada que ver con el feminismo. Ellas atacan la parte del patriarcado que les asesinó los hijos. Nosotras estábamos haciendo otra cosa". ${ }^{27}$

María Elena Oddone fue, sin duda, una figura importante del feminismo de los años setenta, fundadora del Movimiento de Liberación Feminista (MLF) y directora de la única revista feminista de entonces: Persona. En la década siguiente, fundó la OFA (Organización Feminista Argentina) y lanzó la segunda época de Persona. María Elena, durante estas dos décadas, aunque de modo intermitente, se convirtió en una persona pública, más bien mediática, cuyo estilo confrontativo y posicionamiento político generaba conflictos y rechazos desde ciertos sectores del feminismo, y no 
sólo eso. A tal punto que, durante algunos años, en las jornadas anuales (y abiertas) que ATEM realizaba, se exhibía en la puerta del espacio de reunión una pizarra en la que se declaraba que María Elena era considerada persona no grata. Sin embargo, ¿podría afirmarse que se trató solo de la expresión de una militante aislada de aquellos años? Sí y no. Sí, en lo que respecta a su devenir político, en un sentido restringido del término. Oddone, sin admitir una abierta filiación, desde los ochenta comenzó un camino de inclinación hacia sectores de la derecha sin abandonar las banderas del feminismo. Este proceder le fue posible solo a condición de mantenerse de algún modo impenetrable a los cambios que se introducían en la militancia feminista en la década posterior. Las nuevas definiciones de feminismo introducidas con éxito en los ochenta suponían una alianza entre este y las políticas resistentes de las izquierdas. Pero, por otra parte, María Elena no fue una excepción respecto de sus compañeras feministas de los setenta en todos los puntos. Justamente, en lo que respecta a la definición que ella sostenía de feminismo, esta fue compartida por las mujeres del MLF y de la UFA. Si se quiere, María Elena expresó, de una manera radicalizada y hasta caricaturesca, un aspecto de la militancia feminista de los setenta que resultaba inquietante para las feministas posteriores. De hecho, como me lo han hecho saber todas las entrevistas de los años setenta, para ellas la militancia partidaria, aunque fuera de las izquierdas más críticas, reproducía los mismos problemas que el resto de la sociedad, por lo que no había un motivo para sumarse a aquella lucha desde el feminismo.

Los partidos políticos no son destilados teórico-prácticos de los que esté ausente el sexismo [...] La estructura misma de los partidos políticos sigue el esquema de dominación, de definición de las relaciones en términos de lucha, de con y contra, de superior e inferior. [...] Es así que la mujer inserta en un partido político estará incluida en un orden que el de la cultura masculina, que responde, ante todo, al modo en que el varón vive la realidad. ${ }^{28}$

Ahora bien, existe un relato recogido por las páginas de Brujas que se ha canonizado por ser prácticamente la única referencia a un posicionamiento político (en el sentido restringido del término) del feminismo de los setenta. Este relato habla de una "fractura" de la UFA producida en 1973 como consecuencia de diferencias irreconciliables de orden político entre las militantes. Proviene de un testimonio de Sara en ocasión de brindar un relato para las atemas. En esa oportunidad contó que la UFA se fracturó como consecuencia de una sumatoria de eventos sintetizables en dos. En primer lugar, señala los acontecimientos que tuvieron lugar en una reunión plenaria en agosto de 1972 en triste coincidencia con los asesinatos en Trelew de los militantes presos en la cárcel de Rawson, Chubut. Sostuvo que en dicha reunión emergía constantemente el tema de los fusilamientos a pesar de que no eran parte del temario por tratar. También señaló que Gabriela Christeller, quien tenía a su hijo detenido en aquel penal, había asistido a la reunión "destrozada" y en esta situación Leonor habría dicho: "Muertos más, muertos menos, tenemos que seguir peleando en lo nuestro" (Torres, 2006: 86), y que a partir de dicha intervención muchas mujeres habrían abandonado el recinto. En segundo lugar, Sara mencionó las repercusiones que tuvo en el grupo el golpe de Estado al gobierno de Salvador Allende en Chile. Sostuvo que se abrió un debate en torno al comunicado que la UFA sacaría en relación con esa noticia. Algunas mujeres habrían querido sacar una solicitada repudiando la eliminación del nombre del Gabriela Mistral de una plaza o de un calle (según el testimonio) propuesto el gobierno dictatorial. A otras este gesto les habría parecido una trivialización de los sucesos.

La mentada "fractura" cuenta del abandono masivo (para lo que eran los números de la agrupación) de la UFA de personalidades como Gabriela Christeller, Leonor Calvera, María Luisa Bemberg, Safina Newbery, Nelly Brugallo, entre tantas otras.
28. Calvera, L. (1974). Editorial. En Persona, año 1, núm. 2, noviembre p.4. Si bien esta es la publicación de la que Oddone es directora, los primeros dos editoriales los escribió Leonor Calvera, que había participado de la UFA. 
29. Ninguna de las citadas recuerda la anécdota tal como fue contada por Sara. Hilda confiesa que ella no supo que eso pasó pero que luego de leer la Brujas se quedó preocupada por Christeller. Como ya había entrevistado a Gabriela y ella me había confesado que no tenía recuerdo, se lo comenté. Hilda me agradeció y me confesó que se aliviaba mucho, que ese relato la había angustiado por un largo tiempo. Marta Miguelez incluso sugirió algo más cuando hablamos del tema, cito textual: "Sí, pero yo estuve en esta que se arma pero yo estuve en esta que se arma
este despelote, yo estaba. Y en la famosa charla que se comenta lo de Trelew yo no la recuerdo, si estaba no la recuerdo, no la registré. Cosa un poco llamativa porque el cuento es que fue grueso. Si estaba yo no a registré y sino yo no estuve. Esa no hay caso, yo no no estuve... Esa no hay caso, yo no la recuerdo, no lo de Trelew" (Entrevista realizada de Trelew" (Entrevista realizada
por la autora en julio de 2009.).

30. Entrevista realizada por la autora a Marta Miguelez en agosto de 2009.
El objetivo del testimonio producido en Brujas pareciera apuntar a señalar como quiebre de la agrupación diferencias en torno a si debía o no el feminismo tomar partido en las luchas políticas. Y llegó a hablarse de una "politización" del feminismo de aquel período. Sin embargo, esta interpretación no fue compartida por todas. De hecho, todas las que fueron dejando la agrupación lo hicieron en soledad y ninguna dejó asentadas las razones. Al respecto de los puntuales acontecimientos narrados en torno a los desafortunados dichos de Leonor respecto de los asesinatos de Trelew, ni Hilda Rais ni Marta Miguelez recuerdan que hubiera tenido esos tonos, e incluso Gabriela Christeller declaró desconocer aquella intervención. ${ }^{29}$ La idea de una "fractura" da una entidad a aquellos acontecimientos quizá algo desmedida. La "fractura" pareciera hablar de un abierto enfrentamiento político-ideológico entre facciones de la UFA que derivó en distanciamiento; sin embargo, no fue así como se produjo la salida de varias militantes de aquella organización. Cada una cuenta que se fueron "yendo".

Aun así, y en relación con la posible "politización" de la UFA, podría especularse que el contacto que esta organización entabló desde 1972 con el Frente de Liberación Homosexual (FLH) podría haber sido inspirador. El contacto con el FLH fue muy beneficioso para la apertura en ciertas militantes feministas hacia otros campos de preocupación y militancia. Sin embargo, y nuevamente, esta apertura no conllevó necesariamente una explícita redefinición del sentido de la lucha feminista. En la memoria de mis entrevistadas no hay una redefinición del feminismo. Este siguió siendo pensado como una militancia que incumbe a "la mitad de la población" sin ninguna otra determinación. De hecho, dos de las feministas más destacadas de la UFA, después de la fractura de 1973, sostienen esta definición de 'feminismo'. A Sara ya la cité afirmando que lo que buscaban desde la UFA era unirse a partir de lo que tenían en común, y no de las diferencias. Cito ahora a Marta:

si vos eras ama de casa, si eras estudiante, si eras María Luisa Bemberg, ibas a enfocarlo por ahí desde otro ángulo pero es lo mismo. Quiero decir, por ejemplo, obviamente la Bemberg tenía personal doméstico, ella no iba a estar lavando los platos. Pero ella era la responsable de que el trabajo doméstico se hiciera en su casa, no el marido, los hijos. Entonces, podés atravesarlo de otra manera según el nivel socioeconómico, pero lo tenés a tu cargo de todos modos. Esto es lo que de pronto no se entendía mucho para algunos partidos de izquierda en aquel momento y para algunas feministas aún hoy de izquierda esta cosa, para mí el feminismo atraviesa el problema de la clase social. Es otra cosa, es transversal. ${ }^{\circ}$

En todo caso, lo que aconteció fruto del encuentro con el FLH probablemente fue que algunas integrantes de la UFA pudieron expresar más abiertamente sus inquietudes o inclinaciones por agrupaciones políticas, pero no necesariamente como parte de la agenda feminista.

Luego de la "fractura" en la UFA quedaron algo así como cinco integrantes (según mis entrevistas a Hilda Rais, Inés Hercovich, María Mellino y Marta Miguelez) que se dedicaron a realizar tareas más acotadas a sus fuerzas, como grupos de estudio, debate y teatro. De estas reuniones participaban algunas pocas mujeres del PST, que llegaban a partir de los contactos con Sara, y hacia fines de 1976 se sumaron otras que abandonaron el FIP. Pero ninguna de las mujeres de la UFA pensó seriamente en enrolarse en algún partido. Hay una anécdota que me narró Marta Miguelez buscando dar cuenta de su inclinación pero también de sus "límites" para militar por fuera del feminismo.

Yo estaba, fui, de no hacer nada en realidad también participé en una acción con ellos [Montoneros] que era una manifestación acá en el Cid Campeador. Cuando 
llegamos nos viene a buscar una mina... Era en contra de los fusilamientos de Trelew, esa manifestación, ahora que me acuerdo. Me viene a buscar una compañera en auto, cuando estamos llegando al Cid Campeador vemos que la marcha se nos viene encima y con molotov. Pega la vuelta en $U$ y sale corriendo diciéndoles a los autos: “Vuélvanse, vuélvanse, que hay una manifestación”. En lugar de ir a la manifestación parecía que íbamos a boicotear la manifestación. Después había que ir forzosamente al punto en el que teníamos que decir que estábamos vivas. Era en Barracas de Belgrano. Cuando llegamos con el auto, paramos el auto, bajamos en las barrancas y los tanques estaban en la plaza. No, si nosotras como militantes de izquierda, si quisiéramos, seríamos suicidas. ¡Todo al revés hacíamos! [risas]. ${ }^{31}$

Evidentemente, algunas feministas expresaron interés en participar de distintas instancias de militancia político-partidaria; sin embargo, esos intereses no se canalizaban vía sus agrupaciones feministas. Ellas debían, en todo caso, "sumar una militancia más a sus vidas"; así lo recuerda Sara, quien decía de sí misma que era una militante múltiple. El feminismo permaneció como una militancia en torno a una opresión específica que se sostenía poniendo en suspenso cualquier diferencia en el interior del grupo, fuera de clase o ideología política. Este punto fue una diferencia radical con el feminismo que lo sucedió.

\section{Homenaje, deseos y ansiedades sobre el feminismo de los años setenta}

El 9 de octubre de 2002, en el Museo Roca, ubicado en la zona norte de la ciudad, un grupo de académicas y militantes (que ingresaron al feminismo en la década de los ochenta) organizaron un homenaje a las feministas de los años setenta. En las palabras de apertura, hicieron suyas las reflexiones de Luisa Muraro sobre la importancia de la memoria para las construcciones colectivas: "Necesitamos de una mediación para encontrar puntos de referencia que nos ayuden a establecer nuestro lugar-tiempo en el mundo, en relación a y con los otros y para autosignificar, ponerles nombre a nuestras experiencias. En nuestro caso, en este momento, a través de los recuerdos de las vivencias de quienes nos precedieron en las luchas". ${ }^{32}$

En el panel de homenajeadas estuvieron Mirta Henault, Sara Torres, Leonor Calvera y Marta Miguelez. No es un dato menor que la convocatoria fuera solo para la UFA, evitando de este modo la participación de María Elena Oddone, quien igualmente se hizo presente y tomó la palabra en primer lugar luego de las panelistas. Es imposible no notar que el recorte de la convocatoria coincide en algún punto con el que efectuó por años ATEM, agrupación, por otra parte, con la que las académicas tuvieron y tienen importantes contactos. La presencia autoimpuesta de Oddone se constituyó, entonces, en la evidencia de que existía un feminismo - o un aspecto del feminismode los setenta que no era deseable homenajear. Aun a pesar de sus limitaciones, este homenaje fue realmente significativo, incluso, diría, determinante para la construcción de las memorias venideras sobre el feminismo de los setenta. Considérese que las primeras jóvenes historiadoras que luego estudiaron esta experiencia de militancia participaron en este evento y se pusieron en contacto allí con la primera información sobre aquel feminismo que parecía perdido en el olvido.

Como es el riesgo -y casi la condición- de cualquier diálogo, los equívocos y los ruidos se colaron en este evento entre panelistas y auditorio. ¿Cómo se hace para organizar una narración de sí en unos pocos minutos? ¿Por dónde empezar? ¿Qué es lo importante para compartir allí? Sin puentes claros sobre los que construir el relato,
31. Entrevista realizada por la autora en julio de 2009. Los subrayados me pertenecen.
32. Memorias de las Jornadas cedidas por Mónica Tarducci. 
33. Entrevista realizada por la utora en noviembre de 2008 . El mismo testimonio parece haber sido recogido por Alejandra Vassallo (2005) y por Ana María Veiga (2009).

34. Mirta Henualt, en una entrevista que le realicé el enero de 2013, en la que me detuve a indagar sobre las amenazas y persecuciones recibidas, me contó que ella llegó a estar presa, antes de 1970, como consecuencia de la actividad guerrillera de su marido y que luego siempre sintió que estuvo en la mira. Pero ante mi insistente pregunta por si su actividad en Nueva

Mujer había recibido amenazas, fue contundente: “No, no".

35. Gabriela Christeller fue la primera que me aclaró los motivos de aquel allanamiento en una entrevista realizada en abril de 2010. Pero corroboraron esta información Marta Miguelez e Hilda Rais en distintas entrevistas.

36. "En el artículo de Rais [UFA] y Reynoso [MOFEP] se alude al terrorismo de derecha: 'las feministas, en ese período (1975) son calificadas de subversivas - ya no de reacciona-
seriodo (1975) son calificadas de subversivas - ya no de reacciona-
rias-y esto incluye amenazas a una rias-y esto incluye amenazas a una
de ellas, cuya oficina en ese momento era el centro de los grupos'. La amenazada - denuncia Oddone- era

yo, la oficina era la mía, pero estas articulistas omiten mi nombre". (Oddone: 2001, 201). María Elena relaciona las amenazas recibidas con unas volanteadas que había estado haciendo en las puertas de los

colegios secundarios, que tuvieron una repercusión y condena en la revista de ultra derecha Restauración en junio de 1975. Aunque también considera posible causa la protección considera posible causa la protección
que por entonces le brindaba al grupo del Frente de Liberación Homosexual $(\mathrm{FLH})$, permitiéndole usar la oficina para reuniones y como archivo de materiales, después de que la revista de ultraderecha El caudillo condenara

la homosexualidad incenti persecución, en febrero de 1975 . las homenajeadas apenas si pudieron contar algunas "cositas", produciendo narrativas más bien fragmentadas, confusas y algo dispares. Mientras que, por su parte y desde el auditorio, la ansiedad y las expectativas demasiado dirigidas jugaron malas pasadas y entorpecieron la escucha. En muchas ocasiones los silencios de las panelistas fueron "completados" con testimonios provenientes del auditorio, de militantes políticas en los setenta y feministas en los ochenta que intentaban amorosamente establecer similitudes entre sus experiencias y las de las militantes de los setenta sin contar con información. Leonor Calvera se lamentó de la falta de información que existía entre las oyentes y cargó, injustamente, las tintas sobre Sara (por ser quien estuvo en contacto con militantes y académicas del evento): "ahí me di cuenta que Sara no había contado nada". Pero en realidad los puentes entre feministas de los años setenta y las académicas y feministas arribadas de los ochenta estaban rotos desde hacía tiempo y por otros motivos, que ya hemos narrado en los apartados anteriores.

Estas condiciones en las que se produjo el debate (dificultad para narrar la propia experiencia y un auditorio desinformado pero especialmente activo) implicaron que este versara, por un lado, sobre acciones feministas que tuvieron lugar a comienzos de los ochenta (pues buena parte del auditorio solo contaban con información de aquellos años) y, por otro lado, cuando se quiso hacer referencia a los años setenta, la discusión giró en torno a la represión, el estado de terror y la persecución que acosó a las militantes por entonces. Los temas de esta charla estuvieron ligados a las posibilidades de las ahí reunidas.

Importa detenerse en esta última temática, la que se refiere al clima represivo de los setenta, pues varias participantes del auditorio lo recordaron con insistencia, e incluso algunas narraron sus tristes experiencias de exilios. Estas interlocuciones tuvieron también su respuesta por parte de las panelistas, quienes también se refirieron a él. Mirta Henualt contó que su casa estaba amenazada por la Triple A, mientras que Marta Miguelez habló del grado de temor con el que vivía recordando que cada entrada o salida de su departamento implicaba altos grados de alerta.

La referencia a la persecución política del feminismo de los setenta se ha hecho, desde entonces, recurrente tanto en la literatura académica como entre las entrevistadas que, dialógica y tranquilizadoramente, responden a las preguntas que hacemos las investigadoras en ese sentido. Sara Torres, en una de las primeras entrevistas, me comentó que el local que tuvo la UFA hasta 1973, en el barrio de Chacarita, propiedad de la Gabriela Christeller, había sido allanado por la Triple A. ${ }^{33}$ Por su parte, Hilda Rais (militante de la UFA) y Nené Reynoso (exmilitante del FIP) escribieron un artículo en la década de los ochenta en el que explican que en 1975 las feministas eran consideradas como sujetos revolucionarios y que sus locales se encontraban bajo amenaza. Sin embargo, y sin buscar desestimar estos relatos, cuando en mis entrevistas profundicé sobre el asunto de las amenazas y allanamientos, me sorprendí al advertir que: 1) la casa de Henault estaba marcada porque ella no perdió el estigma de haber sido la mujer del "Vasco" Bengoechea, militante guerrillero de Palabra Obrera que murió en un accidente maniobrando una bomba casera;34 2) que los allanamientos al local de la UFA se hicieron (y ellas lo supieron) buscando al hijo de Christeller, que era militante montonero; 35 y 3) que las amenazas de la Triple A a las feministas habían sido, paradójicamente, a María Elena Oddone. ${ }^{36}$

Estas observaciones no contradicen los testimonios existentes porque, por un lado, los ellos han sido lo suficientemente ambiguos y, por otro lado, porque muchas de las feministas sintieron o fueron víctimas de amenazas por algún motivo, aunque a excepción del caso de Oddone, difícilmente podría decirse que fuera como resultado de la militancia feminista. Esta presunción cobra más solidez si se considera que, entre 1981 y 1982, en casa de María Luisa Bemberg, tuvo lugar una reunión de las 
antiguas feministas de la UFA convocada por Emilio Eduardo Massera. ${ }^{37}$ Según mis entrevistadas, la reunión se dio en el marco de la tentativa que hacía Massera respecto de sus posibilidades para armar un partido político en un camino inevitable hacia la democracia, a consecuencia del desgaste que ya vivía el proceso dictatorial. A esta reunión - por temor o por la convicción de que el feminismo era una militancia que podría sostenerse más allá de otras ideologías - asistieron muchas de las militantes. Leonor comentó en entrevista que Bemberg, para calmarlas en caso de que sintieran temor, se habría expresado más o menos con estos términos: "Vengan tranquilas, mi casa es como la embajada de Suiza"..$^{38}$ Esta reunión no puede, de ningún modo, por las tremendas constricciones a las libertades sociales que se vivían, transformarse en un dato para caracterizar la adscripción política de las feministas allí reunidas, pero sí habla de cómo era leído el feminismo por algunos sectores de las fuerzas armadas. ${ }^{39}$

Ahora bien, por otra parte, esta puesta en duda del carácter amenazante del feminismo - a ahora por parte de una sección de las Fuerzas Armadas- no puede, en modo alguno, poner en entredicho tampoco la experiencia del temor que vivieron las militantes feministas en aquel período. Susana Sías Moreno (militante del MLF) narró en su entrevista una experiencia de extremo terror ante un llamado a la puerta de su departamento, en plena noche. Ella acudió a quemar la prensa de PRT-ERP que leía "porque se la dejaba una chica en el local"...$^{40}$ Inés Hercovich, militante primero del MLF y luego de la UFA, me contó otra situación de persecución como consecuencia de la militancia de su marido en Política Obrera (luego Partido Obrero). Leonor Calvera me confesó que ella fue amenazada por la traducción de un libro de filosofía oriental, pero no por feminista. Estos son solo algunos casos, pues prácticamente todas mis entrevistadas vivieron en primera persona alguna situación de persecución o censura. Evidentemente, el clima represivo atravesó, de una u otra manera, la vida de estas mujeres. Ellas fueron, igual que muchos/as otros/as, víctimas de la represión y del terrorismo de Estado. Lo que no es necesariamente claro es que aquella represión estuviera dirigida a su militancia feminista. De hecho, según la propia evaluación de muchas de las feministas de los setenta, a quienes interrogué abiertamente sobre este asunto, el feminismo no fue nunca, salvo el caso de Oddone, explícitamente perseguido por las fuerzas represivas. ${ }^{41}$

¿Por qué estas ambigüedades en torno a persecución y amenazas en las narrativas de las feministas? ¿Y por qué puede ser importante detenerse en ellas? En primer lugar, porque es una posibilidad que las narrativas que sugieren amenazas y persecución política al feminismo hayan sido el modo encontrado para valorizar la experiencia o para que ella fuera audible para quienes hoy demandan aquellas memorias. Esta ha sido, al menos, mi experiencia con entrevistadas del período. Afirmar esto no supone, de ningún modo, insinuar que las memorias construidas por las feministas fueran "falsas", predicaciones que no les caben a los testimonios. Como han explicado extensamente Leonor Arfuch (2010) y Alicia Lindon (1999) en sus respectivos trabajos, los testimonios o relatos de vida suponen necesariamente procesos de armonización retrospectiva de la propia historia en función de los/as interlocutores/as reales o imaginados/as. Y esta armonización no constituye una parte desechable del testimonio, sino una pieza fundamental por analizar en el relato. En segundo lugar, detenerse sobre las ambiguas narrativas de persecución construidas sobre la experiencia feminista de los setenta es importante porque ellas se han convertido en una suerte de prueba con pretensiones de autoevidencia respecto del carácter político (en el sentido restringido del término) del feminismo de aquellos años y de sus supuestos vínculos con otras militancias desarrolladas desde sectores de las izquierdas en el proceso de radicalización política. Esta ligera asociación ha tenido el efecto de alejar al feminismo de procesos culturales con los que estuvo bastante más relacionado, como es el proceso de modernización sociocultural.
37. Emilio Eduardo Massera fue un militar argentino quien, entre 1976 y 1978 , formó parte de la junta 1976 y 1978, formó parte de la junta de Perón. Fue enjuiciado por la responsabilidad de numerosos crímenes de lesa humanidad.

38. Entrevista realizada por la autora a Leonor Calvera en diciembre de 2012.

39. Solo algunas de las entrevistadas me hablaron de esta reunión, entre ellas María Inés Aldaburu (quien se contactó con el feminismo en tiempos de dictadura militar y luego fue parte del OFA) y Leonor Calvera, quien pudo darme los detalles porque participó de dicha reunión. como un sin-sentido. De él, dice, que no prosperó nada. Recuerda que lo más concreto que se charló fue una invitación a colaborar con notas sobre feminismo para una publicación que Massera financiaba, pero la mayoría allí reunidas -incluida Leonor- declinaron la invitación.

40. Entrevista realizada en noviembre de 2009.

41. Pregunté abiertamente si la militancia feminista había sido amenazada y/o perseguida por las Fuerzas Armadas a Christeller. Calvera, Mellino, Hercovich Aldaburu, Henault y Miguelez. 
42. Véanse los trabajos de Vassallo (2005), Grammático (2005), Rodríguez Agüero (2013), Feijóo y Sanchez, Freytes, Veiga (2009), etc.

\section{Algunas palabras finales}

Como comenzamos señalando a partir de las investigaciones de Chaperon y Pedro, en Francia y en Brasil, las genealogías del feminismo han sido y son un campo de disputas en el que se encuentran comprometidas testimoniantes y demandantes de aquellos testimonios. El caso local no constituye una excepción. En este artículo procuré evidenciar algunas de las batallas en torno a las memorias del feminismo de los setenta emprendidas por el feminismo posterior, que estuvieron sostenidas a partir de ciertos desacuerdos respecto del sentido del feminismo. Al mismo tiempo intenté señalar algunos desencuentros entre aquel feminismo de los setenta y los relatos construidos desde la academia, que se produjeron especialmente a efecto de encontrarse rotos los puentes entre aquella experiencia y las sucesoras que sí entraron en contacto con la academia. Desde la academia, y ante el vacío de relatos disponibles, investigadoras y feministas con el deseo de recuperar al feminismo de los setenta con un signo positivo, y guiadas asimismo por las memorias producidas por las atemas, terminaron inscribiendo dicha experiencia de militancia junto a otras propias del llamado proceso de radicalización política y aislándola de otros procesos igual o más influyentes en su desarrollo. ${ }^{42}$ Esto produjo, a mi entender, una invisibilización de personajes (como Oddone) y de propuestas que resultaban discrepantes de dicha lectura.

Finalmente, fue necesario advertir sobre el carácter activo y estratégico de las testimoniantes en el proceso de producción de sus relatos. Ellas debieron producir procesos de armonización, como explica Lindon (1999), en función de la escucha que hallaron disponible y de las expectativas de las demandantes. Laura Masson, al analizar la bibliografía historiográfica sobre el feminismo de los setenta, declara sentirse sorprendida ante la valoración negativa que podía leer entre líneas acerca de una posible escisión de las feministas respecto de la militancia de las izquierdas (2007: 151). Estas expectativas sobre la militancia feminista de los setenta probablemente hayan alcanzado e influenciado a las propias testimoniantes. Considerando la información reunida en este trabajo, proveniente de entrevistas y trabajo de campo, podría hipotetizarse que las ambigüedades de algunos relatos persiguen como objeto poner en valor la experiencia pasada en relación con sucesos que fueron de trascendida importancia a partir de los ochenta. Al abrevar en el campo el campo epistémico de los estudios de memoria, este trabajo no buscó producir una denuncia de sesgo positivista en torno a la búsqueda de una narrativa de pretendido carácter verdadero, sino que procuró poner bajo lupa los diversos procedimientos implicados en la construcción de las narrativas del pasado feminista de la ciudad de Buenos Aires.

Las genealogías, las memorias o los distintos modos en que narramos nuestra historia conllevan procedimientos activos, más o menos conscientes, pero también y en tanto y en cuanto en ellos se (nos) juegan aspectos primarios, dimensiones identitarias, estos procedimientos se despliegan atropellando nuestras voliciones y racionalizaciones. Hablar de sí, contar la propia historia o trazar una línea de herencia y producir una genealogía son actividades que no se producen a partir de la mera apelación a la memoria del factum o a partir de la simple reunión de datos. Poder dar cuenta de la complejidad de los procedimientos implicados en la producción de narrativas del pasado fue el objetivo del presente trabajo. 
"Arfuch, L. (2010). El espacio biográfico. Dilemas de la subjetividad contemporánea. Buenos Aires, Fondo de Cultura Económica.

"Besse, J. y Trebisacce, C. (2013). Feminismo, peronismo. Escrituras, militancias y figuras arcaicas de la poscolonialidad en dos revistas argentinas. En Debate Feminista, año 24, vol. 47, abril, pp. 237-264. Ciudad de México.

"Candau, J. (2002). Antropología de la memoria. Buenos Aires, Nueva Visión.

»Cano, I. (1982). El movimiento feminista argentino en la década del '70. En Todo es Historia, núm. 183, agosto. Buenos Aires.

"Chaperon, S. (1995). La radicalisation des mouvements féminins français de 1960 à 1970. En Vingtième Siècle. Revue d'historie, vol. 48, núm. 1, pp. 61-74.

»Chejter, S. (1996). “Los setenta”, en revista Travesía, Feminismo por feministas, nำ , Buenos Aires, pp 9-26.

»Diana, M (1996) Mujeres guerrilleras. La militancia de los setenta en el testimonio de sus protagonistas femeninas, Buenos Aires, Planeta.Feijoo, L. y Sanchez, A. (2007). „Feminismo y socialismo en los '70: La experiencia de la izquierda socialista en el movimiento de mujeres " en Actas de las XI Jornadas Interescuelas/ Departamento de Historia, Tucumán.

" Franco, M. (2008). El exilio. Argentinos en Francia durante la dictadura. Buenos Aires, Siglo XXI.

» Freytes, N. (2007) Entre lo público y lo privado, lo personal y lo político. Un acercamiento a la militancia femenina de los años '70 en Actas de las IV Jornadas de Jóvenes Investigadores, Buenos Aires.

"Grammático, K. (2005). Las mujeres políticas y las feministas en los tempranos setenta: ¿un diálogo (im)posible?. En Andújar, A. et al., Historia, género y política en los 70, pp. 19-38. Buenos Aires, Feminaria.

»Lindon, A. (1999). Narrativas autobiográficas, memoria y mitos: una aproximación a la acción social. En Revista Economía, Sociedad y Territorio, vol. II, núm. 6. México.

" Masson, L. (2007). Feministas en todas partes. Una etnografía de espacios y narrativas feministas en Argentina. Buenos Aires, Prometeo.

"Pedro, J. M. (2006). Narrativas fundadoras do feminismo: poderes e conflictos (1970-1978). En Revista Brasileira de Historia, vol. 26, núm. 52, pp. 249-272. San Pablo.

»Rodríguez Agüero, L. (2013). Mujeres, feminismos e izquierdas. En Feminismos del sur. Mujeres, política y cultura en la Argentina de los ,70. Málaga, Servicio de publicaciones de la Universidad de Málaga.

"Trebisacce, C. (2013a). Encuentros y desencuentros entre la militancia de izquierda y el feminismo en la argentina. En Estudos Feministas, mayo, pp. 432462. Florianópolis.

»--------(2013b). Un fantasma recorre la izquierda nacional. Feminismo de la segunda ola y la lucha política en Argentina en los años setenta. En Sociedad y Economía. Dossier: Estudios de Género y sexualidad, núm. 24, julio, pp. 95-120. Cali. 
---------- Revoluciones simbólicas y de militancia en las feministas porteñas de los setenta. En Tarducci, M. (comp.). Feminismo, lesbianismo y maternidad en Argentina, pp. 7-36. Buenos Aires, Feminaria.

»Vassallo, A. (2005). Las mujeres dicen basta: movilización, política y orígenes del feminismo argentino en los '70. En Andújar, A. et. al. Historia, género y política en los 70. Buenos Aires, Feminiaria.

»Veiga, A. M. (2009) Feminismos em rede? Uma história da circulação de discursos e informações entre São Paulo e Buenos Aires (1970-1985). . Dissertação (Mestrado em História) - Programa de Pós-Graduação em História Florianópolis. Universidade Federal de Santa Catarina.

\section{Fuentes}

»AA. VV. Brujas, núms.1 al 38.

»Barancchini, D. (1973). María Luisa Bemberg. UFA con los hombres! En Claudia, julio.

"Oddone, María Elena La pasión por la Libertad, memorias de una feminista, Buenos Aires, Ediciones Colihue, 2001

»Torres, Sara (2006) „Mujeres socialestas en la UFA: otra mirada. Entrevista a Sara Torres“ en Brujas, año 25, n 32, pp. 83-90.

»Entrevistas a: Sara Torres (UFA), Leonor Calvera (UFA), Gabriela Christeller (UFA), Marta Migulez (UFA), Mirta Henault (Nueva Mujer-UFA), Inés Hercovich (MLF-UFA), María Mellino (UFA), Susana Sías Moreno (MLF), María Elena Oddone (MLF), María Inés Aldaburru (MLF).

»Desgrabración de las Jornadas Homenaje al Feminismo de los ‘70, octubre de 2002. 